\section{Estimate of the Influx of Extraterrestrial Material during the Silurian}

Parkin and Tilles ${ }^{1}$ recently described the methods used for measuring the influx of extraterrestrial material to the Earth's surface and discussed critically the significance of the results so far obtained. In particular, they mentioned unpublished work by J. L. Barker, in which the abundances of osmium and iridium in deep sea sediments had been applied to the estimation of the infall rate. This was of interest because, in the course of an extensive study of the distribution of rhenium and osmium in rocks ${ }^{2}$, the abundances of trace elements in a Silurian shale had been applied in a similar way. Although the relevant data required for the calculation have been published previously ${ }^{3-6}$ the result has not, and to do so is the intention of this communication.

As part of a neutron activation study of rhenium and osmium abundances in tektites and possible tektite parent materials $^{3}$, a shale from the State Circle formation ${ }^{7}$, Etheridge Creek, Australian Capital Territory, Australia, was investigated. The actual specimen analysed was described as sample 13 by Compston and Pidgeon ${ }^{4}$, and was found to contain $0.5 \times 10^{-10} \mathrm{~g}$ of Re and $4.5 \times 10^{-10} \mathrm{~g}$ of Os per $g$ of specimen. These abundances yield an atomic $\mathrm{Os} / \mathrm{Re}$ ratio of $8 \cdot 7$, and it was this that first suggested that the observed abundances might have an extraterrestrial origin. Recent work ${ }^{5}$, in which simultaneous neutron activation analyses were made on thirtytwo observed chondrite falls, established a mean "cosmic" (meaning solar system) Os/Re ratio of $11 \cdot 4 \pm 1 \cdot 3$. On the other hand, all common crustal rock types so far analysed ${ }^{6}$ have ratios of unity or less. It therefore seems that, apart from contrived assumptions involving addition of osmiumrich material from ultrabasic sources, a chondritic origin for the rhenium and osmium in the State Circle shale is the most plausible.

Goldschmidt ${ }^{8}$, when proposing the application of rare metal abundances in sediments to the estimation of the influx of extraterrestrial material, stressed that the sedi-

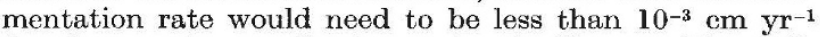
for the cosmic contribution to be significant. The sedimentation rate of the State Circle shale can be estimated. Compston and Pidgeon ${ }^{4}$ measured the age of the formation as $425 \times 10^{6} \mathrm{yr}$ by a total rock rubidium-strontium method. They suggested that one shale specimen taken from $70 \mathrm{ft}$ higher up in the section than the others analysed may be 1 or 2 per cent younger. If this estimate is reasonably accurate, one can say that $70 \mathrm{ft}$ represents $1 \cdot 5 \pm 0.5$ per cent of $425 \times 10^{6} \mathrm{yr}$. This corresponds to a deposition rate of $(3 \cdot 3 \pm 1 \cdot 1) \times 10^{-4} \mathrm{~cm} \mathrm{yr}^{-1}$, a value well within that required for tho extraterrestrial contribution to the rare metal abundances to be high enough for an influx estimation.

Goldschmidt expressed the reservation that contamination of sediments by andesitic dust might completely mask any effect on trace abundances, caused by extraterrestrial material. The US Geological Survey standard andesite $A G V \cdot 1$ has been shown to contain $3.4 \times 10^{-10} \mathrm{~g}$ of $\operatorname{Re} \mathrm{g}^{-1}$ and $\leqslant 0 \cdot 24 \times 10^{-10} \mathrm{~g}$ of $\mathrm{Os} \mathrm{g}^{-1}$, and it is clear that the Os/Re ratio in this rock is very much lower than that observed in the State Circle shale. If $A G V \cdot 1$ is typical of andesites, rhenium contamination of the sediment is a possibility which must be considered. The magnitude of this contamination cannot be very large in the State Circle shale as the Os/Re ratio is close to the chondritic one. Possibly the slightly lower shale ratio is due to some 20 per cent of the rhenium in the sediment being contamination from terrestrial rocks. In the case of osmium the probability of a significant contribution from andesitic sources can be rejected. Because of this, and the relatively high abundanee of osmium in chondritie material, this element seems to be a much more satisfactory indicator than rhenium, and is the basis of the following discussion.
The rate at which osmium is added to the sedimentary column can easily be estimated. If a typical shale density of $2.65 \mathrm{~g} \mathrm{~cm}^{-3}$ is assumed, then, from the shale abundance of $(4 \cdot 5 \pm 1 \cdot 1) \times 10^{-10} \mathrm{~g}$ of $\mathrm{Os} \mathrm{g}^{-1}$ and sedimentation rate of $(3.3 \pm 1 \cdot 1) \times 10^{-4} \mathrm{~cm} \mathrm{yr}^{-1}$, the rate at which osmium is deposited is $(4 \cdot 0 \pm 1 \cdot 6) \times 10^{-13} \mathrm{~g} \mathrm{~cm}^{-2} \mathrm{yr}^{-1}$.

The chondritic abundance of osmium is now well established ${ }^{5}$ and has a value of $0.61 \mathrm{Os}$ atoms per $10^{6} \mathrm{Si}$ atoms. If it is assumed that the infalling material is similar to the ordinary $H$ and $L$ group chondrites in composition, then a silicon content of 17.5 per cent ${ }^{9}$ can be used without introducing significant error. The mean osmium weight abundance is then $0.72 \times 10^{-6} \mathrm{~g}$ of $\mathrm{Os} \mathrm{g}^{-1}$. From this value and the osmium deposition rate, the rate of influx of extraterrestrial material is then $(5 \cdot 6 \pm 2 \cdot 3) \times 10^{-7} \mathrm{~g} \mathrm{~cm}^{-2} \mathrm{yr}^{-1}$. The total area of the Earth's surface is $5.1 \times 10^{18} \mathrm{~cm}^{2}$; therefore, if uniform infall over the whole surface is assumed, a total influx of $(2 \cdot 8 \pm 1 \cdot 1) \times$ $10^{12} \mathrm{~g} \mathrm{yr}^{-1}$ or $(8 \pm 3) \times 10^{3}$ tons day ${ }^{-1}$ is found.

Although most of the observed chondritic falls are from the $H$ and $L$ groups, it is widely considered that the carbonaceous chondrites, particularly of Type I, may more closely represent "primitive cosmic" material. Observed falls of Type I carbonaceous chondrites are very rare, but because of their very friable nature it is possible that this material is much more abundant than the small number of specimens recovered intact might indicate. If the influx calculation is repeated using the osmium abundance of $0.45 \times 10^{-6} \mathrm{~g}$ of $\mathrm{Os} \mathrm{g}^{-1}$ found in the Orgueil Type I carbonaceous chondrite, the rate is $(1 \cdot 2 \pm 0 \cdot 5) \times 10^{4}$ tons day $^{-1}$. It should be noted that no attempt has been made to introduce a factor to account for any latitude dependence of the influx rate. There seem to be no reliable palaeomagnetic determinations of Silurian pole positions for Australian rocks, and in any case it seems unlikely that the present day latitude dependence can be assumed to have remained unchanged over the past $425 \times 10^{6} \mathrm{yr}$.

It is interesting to compare the present estimate with those for the "present day" rate discussed by Parkin and Tilles ${ }^{1}$, whose paper should be consulted for detailed references. The only work similar to that described here is the unpublished study by Barker. He suggests that a value of $3 \times 10^{2}$ tons day $^{-1}$ is probably correct within a factor of 3 , that is, a rate of between $10^{2}$ and $10^{3}$ tons day $^{-1}$. Other estimates based on ${ }^{26} \mathrm{Al},{ }^{38} \mathrm{Cl}$ and nickel in sea sediments, and rare gas anomalies in dust, all lead to upper limits for the influx rate of between $10^{3}$ to $10^{4}$ tons day $^{-1}$. The measurement of nickel in Antarctic ice gives a rate of $10^{4}$ tons day $^{-1}$ on a uniform accretion and fallout model. A realistic estimate of the present day influx rate would therefore be $\leqslant 10^{4}$ tons day ${ }^{-1}$. This is in good agreement with the value for the Silurian shale, and indicates that the influx rate has been constant, to within a factor of 10 or so, for the past $400 \times 10^{6} \mathrm{yr}$. Admittedly the estimate made here is based only on the duplicate analysis of a single sample and on a very approximate sedimentation rate; nevertheless it does clearly indicate the way in which neutron activation analyses of sedimentary rocks may be applied to "palaeometeorities".

\section{J. W. Morgan}

Chemistry Division,

Australian Atomic Energy Commission,

New South Wales, Australia.

Received May 20, 1968.

${ }^{1}$ Parkin, D. W., and Tilles, D., Science, 159, 930 (1968).

"Morgan, J. W., thesis, Australian National Univ., Canberra.

Lovering, J. F., and Morgan, J. W., Geochim. Cosmochim. Acta, 28, 761 (1964).

4 Compston, W., and Pidgeon, R. T., J. Geophys. Res., 67, 3493 (1962).

${ }^{5}$ Morgan, J. W., and Lovering, J. F., Geochim. Cosmochim. Acta, 31, 1893 (1967).

- Morgan, J. W., and Lovering, J. F, Earth Plan. Sci. Lett., 3, 219 (1967).

$?$ Öpik, A. A., Bulletin 32 (Bureau of Mineral Resources, Australia, 1958).

${ }^{8}$ Goldschmidt, V. M., Geochemistry (edit. by Muir, A.) (Oxford University Press, London, 1954).

'Vogt, J. R., and Ehmann, W. D., Geochim. Cosmochim. Acta, 29, 373 (1965) 